\title{
Effectiveness of mycofiltration for removal of contaminants from water: a systematic review protocol
}

\author{
Sanele Michelle Mnkandla $a^{1,2^{*}}$ (1) and Patricks Voua Otomo
}

\begin{abstract}
Background: Mycofiltration is an environment friendly technology which involves the treatment of contaminated water by passing it through a network of fungal mycelium. This technology has gained momentum over the years, and the systematic review chartered in this protocol will compile and synthesise literature on mycofiltration studies, paying special attention to the types and levels of contaminants removed. The systematic review should provide insight into the removal efficiency of mycofiltration by synthesising the mycofiltration knowledge base. Moreover, the proposed contribution will inform further research and provide comprehensive information to relevant stakeholders, such as municipalities, which might be in need of interventions for alleviating wastewater-related pollution in surrounding water bodies.

Methods: This systematic review protocol is based on the question, "What is the effectiveness of mycofiltration for removal of contaminants from water?" A thorough search of peer reviewed journal articles and grey literature sources will be conducted on academic journal databases, websites, specialist sources such as environmental organisations as well social and networking sources. A supplemental search will also be performed by forward and backward citation tracing. A two-stage screening process at title, abstract and full text level, will be conducted, against predefined inclusion criteria. Studies that meet inclusion criteria will be subjected to quality assessment. Data will be extracted and compiled into a narrative synthesis and summarised into tables and figures. Meta-analysis will be performed where sufficient evidence-base allows.
\end{abstract}

Keywords: Mycofiltration, Contaminated water, Systematic review, Effectiveness

\section{Background}

Ground water and surface water sources, such as dams, rivers, lakes and canals, serve as important sources of the world's drinking water $[1,2]$. Treated (urban) or untreated (rural) surface water can be used for drinking, irrigation for farmers, fishing, as well as hold aesthetic value as tourist attractions [2]. It thus becomes of great

\footnotetext{
*Correspondence: sanelemnkandla@gmail.com

${ }^{1}$ Ecotoxicology Research Group, Afromontane Research Unit, Faculty of Natural and Agricultural Sciences, University of the Free State, Qwaqwa, South Africa

Full list of author information is available at the end of the article
}

importance, that good water quality, i.e., the chemical, physical as well as biological characteristics, is attained, because it influences the health status of any ecosystem [1].

While natural water quality differs from one place to another, depending on, e.g., change in seasons, climate, geochemical settings and biochemical processes, anthropogenic activities add to the differences that ultimately change the water use potential $[2,3]$. Such activities include mining, agriculture, as well as industry. According to Akpor and colleagues [4], raw and partially treated wastewater released from industry are one of the major point sources of surface water pollution. This original author(s) and the source, provide a link to the Creative Commons licence, and indicate if changes were made. The images or other third party material in this article are included in the article's Creative Commons licence, unless indicated otherwise in a credit line to the material. If material is not included in the article's Creative Commons licence and your intended use is not permitted by statutory regulation or exceeds the permitted use, you will need to obtain permission directly from the copyright holder. To view a copy of this licence, visit http://creativecommons.org/licenses/by/4.0/. The Creative Commons Public Domain Dedication waiver (http://creativeco mmons.org/publicdomain/zero/1.0/) applies to the data made available in this article, unless otherwise stated in a credit line to the data. 
is particularly common in developing countries. Wastewater contains harmful microorganisms, pharmaceuticals, personal care products, as well as heavy metals, $[2$, 5]. Wastewater treatment plants (WWTPs) that serve to recycle and release wastewater effluents with little effect on the surrounding ecosystem, tend to release effluent that is often inadvertently contaminated with toxic inorganic compounds, largely due to poor plant designs and inadequate wastewater management systems $[4,6]$. In addition to effluent discharge, are nonpoint source pollutants, which also contribute to the pollution of surface water. With the quest for improved agricultural productivity fertilizers and pesticides are employed. When rainfall or irrigation water runs over land, it moves and deposits pesticides and nutrients into nearby water bodies $[4,6]$. These pollutants disturb the health of the ecosystem, which necessitates interventions to alleviate the burden.

In recent years, biological technologies involving manipulation of naturally occurring microorganisms, such as fungi, to remove pollutants have been advocated [4]. Fungi are eukaryotes which may exist as individual cells, e.g., yeasts or as long chains of cells [7]. Saprophytic fungi grow on dead organic matter and take up nutrients by excreting digestive enzymes that break down complex nutrients to simpler forms [7]. Fungi are known for being adaptable organisms, with an ability to grow under environmental conditions of stress, and have become handy for bioremediation purposes [8].

Fungal mycelium are said to employ mechanisms such as biosorption, bioaccumulation and biodegradation in the remediation of pollutants/ xenobiotics $[9,10]$. Biosorption, a passive process, occurs on the cell surface by ion exchange and complexation reactions with functional groups such as carboxyl, amine, hydroxyl and phosphate groups [11]. Bioaccumulation is an active metabolism dependent process, which involves transport of pollutants into the cells and partitioning into intracellular components [9]. The biodegradation mechanism entails the degradation of non-polymeric, recalcitrant pollutants to simpler elements by extracellular enzymes [9]. Several species of fungi have been studied and have demonstrated an exceptional ability in the uptake and removal of metals and other pollutants from waste and/ or runoff water [1]. Fungal species, either live or in the form of dried biomass, have a very effective biosorption potential for metals such as $\mathrm{Cu}, \mathrm{Zn}, \mathrm{Fe}$ and $\mathrm{Mn}$, and hold the ability to transform recalcitrant pharmaceutical compounds, as well as breakdown pesticides [12-14].

The use of fungi to degrade or sequester environmental pollutants, i.e., mycoremediation, has thus been deemed a technique that is not only cost-effective, but involves natural processes that do not produce toxic by-products
[8]. One method of using fungi in mycoremediation is known as Mycofiltration, i.e., the treatment of contaminated water by passing it through a network of fungal mycelium [15]. A typical mycofilter comprises a burlap sack layered with substrate (e.g., straw or woodchips) and saprophytic mycelium [16]. The mycelium grows throughout the sack as a network of filaments, before being placed in the water bodies for remediation. Mycofiltration has shown to efficiently remove microbial pathogens from storm water, treat industrial brewery effluent, remediate heavy metal contaminated drinking water sources, as well as remove total nitrogen and phosphorus from a dairy lagoon waste $[1,15,17-19]$.

Mycofiltration therefore has potential for use, to filter out and reduce levels of organic, inorganic and microbial contaminants in water. A synthesis of the evidence on mycofiltration of contaminated water via a systematic review will provide reliable and accurate data on the types of contaminants removed, and the mycofiltration removal efficiency based on a comparison of the levels of contaminants before and after filtration. The proposed systematic review will be conducted as part of an effort in the advancement of bioremediation interventions in the Maluti-a-Phofung municipality of eastern Free State of South Africa. Municipal reports of the Maluti-a-Phofung municipality show high WWTP-linked pollution events that subsequently affect the surrounding aquatic ecosystem health $[20,21]$, thus indicating a need for an intervention. The municipal authorities will be made aware of the preliminary review findings and bilateral discussions will help determine whether the mycofiltration technology could be adopted locally as a remediation tool for WWTP-linked pollution. The review findings will also have relevance to other stakeholders, such as researchers and environmentalists, interested in biological remediation interventions.

\section{Objective}

The objective of the systematic review is to collate existing research on mycofiltration and assess its efficiency in the removal of specific contaminants/ pollutants in water and/ or wastewater effluent. The review will also ascertain any knowledge gaps for future primary research areas.

\section{Main question}

What is the effectiveness of mycofiltration for removal of contaminants from water?

\section{Secondary question}

What contaminants are removed by mycofiltration? 


\section{Components of the question}

Population: Any water bodies contaminated with organic, inorganic and microbial pollutants.

Intervention: The use of any fungal species in the mycofiltration technology to filter out contaminants in water.

Comparator: Control with no intervention (i.e., no biological filter).

Outcome: Types and levels of contaminants removed in mycofiltered water.

\section{Methods}

\section{Searching for articles}

The systematic review will follow the Collaboration for Environmental Evidence (CEE) guidelines [22] and will conform to the ROSES checklist (Additional file 1).

The search aims to retrieve a wide range of quantitative scientific evidence, i.e., peer reviewed articles and grey literature, covering the topic of mycofiltration and its effectiveness.

\section{Search terms and language}

The search will be conducted in English. The review will target publications, reports, theses and books written in English, from any geographical area, between the year 1990 to 2021. This period covers the earliest to the latest contributions in the subject area.

The search terms/ keywords that will be used to search for relevant literature are broken into two components: the intervention and the population, and will be combined using Boolean operators "AND" and/ or "OR". The comparator and outcome will not be used as part of the search strategy, because comparator terms are not often explicitly stated in titles and abstracts; and the outcome is not always predictable, as there is a possible wide range of the types and levels of contaminants that could be removed by mycofiltration.

Intervention terms: Mycofiltration, mycofilter, fungal filter, fungal filtration, fungal bioremediation, mushroom filtration, mycelium filter, mycelium colonized.

Population terms: borehole pollution, river pollution, dam pollution, pond pollution, contaminated water, water pollution, polluted water, stormwater, rainwater, wastewater, effluent, untreated water, treated water, synthetic water.

Where applicable, search terms will be truncated, and an asterisk will be used as a wild card at the end, to obtain alternative forms of the words (e.g. mycofilt ${ }^{*}=$ to include mycofilter, mycofiltration).

The final search string will be:

("mycofilt" " OR "fungal filter" OR "fungal filtration" OR "fungal bioremediation" OR "mushroom filtration" OR "myceli" filter" OR "mycelium colonised") AND ("borehole pollution" OR "river pollution" OR "dam pollution" OR "pond pollution" OR "contaminated water" OR "water pollution" OR "polluted water" OR "stormwater" OR "rainwater" OR "wastewater" OR "effluent" OR "untreated water" OR "treated water" OR "synthetic water").

The specific search strings used with each database are listed in Additional file 3. Where a complex search string is not accepted, the search string used will be adapted to valid syntax in each database. Modified search strings will be recorded.

\section{Academic databases and websites}

The search will be conducted using these databases:

1. Science Direct

2. Scopus

3. PubMed

4. Web of Science Core Collection

5. Open Access Theses and Dissertations (https://oatd. org/)

An internet search will be carried out using Google Scholar.

Websites of the following organisations involved in environmental studies and remediation interventions will be searched for relevant literature:

6. Fungi perfecti (https://fungi.com/)

7. United States Environmental Protection Agency (https://www.epa.gov/)

8. International Organisation for Standardisation (https://www.iso.org/)

9. Organisation for Economic Cooperation and Development (https://www.oecd.org/)

10. Hab Research (https://habprevention.weebly.com)

11. The Water Network (thewaternetwork.com)

\section{Social and research networking sources}

The following social and research network sources, where companies, researchers and other users share their interests and contributions, will be searched. Hashtags (\#) will be used to search Twitter and Facebook (e.g., \#mycofiltration, \#fungalbioremediation etc.), while keywords and simple strings will be employed in searching ResearchGate and Academia (e.g. "mycofilter", "mycofiltration and contaminated water" etc.,). The hashtags and keywords used will be recorded in the final review.

12. Twitter (https://twitter.com)

13. Facebook (https://www.facebook.com/)

14. ResearchGate (https://www.researchgate.net/) 


\section{Academia (https://www.academia.edu/)}

\section{Supplementary searches}

Forward and backward citation tracing will be conducted on all literature retrieved using the search strategy, to find further relevant articles.

\section{Estimating the comprehensiveness of the search}

The comprehensiveness of each search attempt will be evaluated against its ability to return eleven key scientific papers of known relevance to mycofiltration (see Additional file 2). The articles were previously identified by the review members, as authoritative studies in the subject area. If benchmark studies are found to be missing from the search, the search string will be adapted.

\section{Article screening and study eligibility criteria Screening process}

The search results will be exported to the EndNote X7 reference manager, and any duplicates present will be removed. The collected articles will be subjected to two levels of screening. The first level will be title and abstract, while the second will be full text. Screening results will be checked for consistency and clarity independently, by the two reviewers. The checks will be done at each screening level, on a random subset of $10 \%$ of the total records. If the $10 \%$ represents too small a subset, we will increase the sample size to 100. Any disagreements or ambiguity will be resolved through dialogue between review team members. A Cohen's Kappa score of $\geq 0.6$ will indicate agreement between reviewers. A reviewer who is an author of a study will not be allowed to decide on the inclusion of that particular article. In such a case, a scholar with expertise in the subject will be enlisted to adjudicate. Records of the number of articles excluded and reasons for their exclusion, at full text level, will be provided as supplementary material.

\section{Eligibility criteria}

For a study to be included in the systematic review, it must be written in English and fall between the year 1990 and 2021. It also must meet the following inclusion criteria:

Eligible population: Contaminated/ polluted water and/ or effluent.

Eligible intervention: Mycofiltration; the use of fungi as filters to clean up contaminants/ pollutants in water and/ or effluents.

Eligible comparator: No intervention.

Eligible outcome: The types and concentrations of contaminants/ pollutants removed in the mycofiltered water.
Eligible study types: Both field and laboratory studies that implement mycofiltration, and show comparison to comparator i.e., no mycofiltration will be included.

\section{Study validity assessment}

Studies deemed eligible based on the population, intervention, study design and outcome will be subjected to critical appraisal. Quantitative studies will be assessed on internal study validity (i.e., susceptibility to bias). The CEE Critical Appraisal Tool Version 0.2 (Prototype) [23], modified to our review question, will be used for study validity. Each study will be evaluated against a set of six criterion, and the related checklist questions as outlined in Table 1: (1) Study design: Was there a sufficient number of replicates per experiment?, (2) Risk of confounding: Are confounding variables (temperature, seasons, $\mathrm{pH}$ of sample, pre-treatment of mycofilter) accounted for?, (3) Risk of misclassification bias: Is the intervention clearly defined (i.e., fungal species used)?; (4) Risk of performance bias: Is there a clear link between hypothesis and measured outcomes?, (5) Risk of reporting bias: Is the reported effect estimate based on selected measurements of the outcome?, Is there clarity of measured outcomes before vs after intervention (i.e., no missing data)?, (6) Risk of analysis bias: Is there sufficient description of statistical analysis and results?

The data on these set parameters will be extracted and entered in a MS Excel spreadsheet. Each parameter within a study will be graded as 'low validity', 'medium validity' and 'high validity' based on the outputs listed in Table 1. To determine overall judgement on the validity of a study; a study that records: (a) high validity on all parameters, will be considered of high validity, (b) medium validity in at least one parameter, but not low validity for any other parameters, will be considered of medium validity, (c) low validity in at least one parameter, will be considered of low validity. All information on validity assessment and rejected studies (based on validity) will be recorded and presented in the final review. Rejected studies will not be included for data extraction.

External validity (i.e., extent to which a study appropriately answers the review question) will be assessed during full text screening using the eligibility criteria in the section above.

Both reviewers will conduct critical appraisal on a subset of $10 \%$ (or more) of the studies. One reviewer will conduct the exercise, and the other will check and validate the decisions. Any disagreements will be discussed between reviewers. 


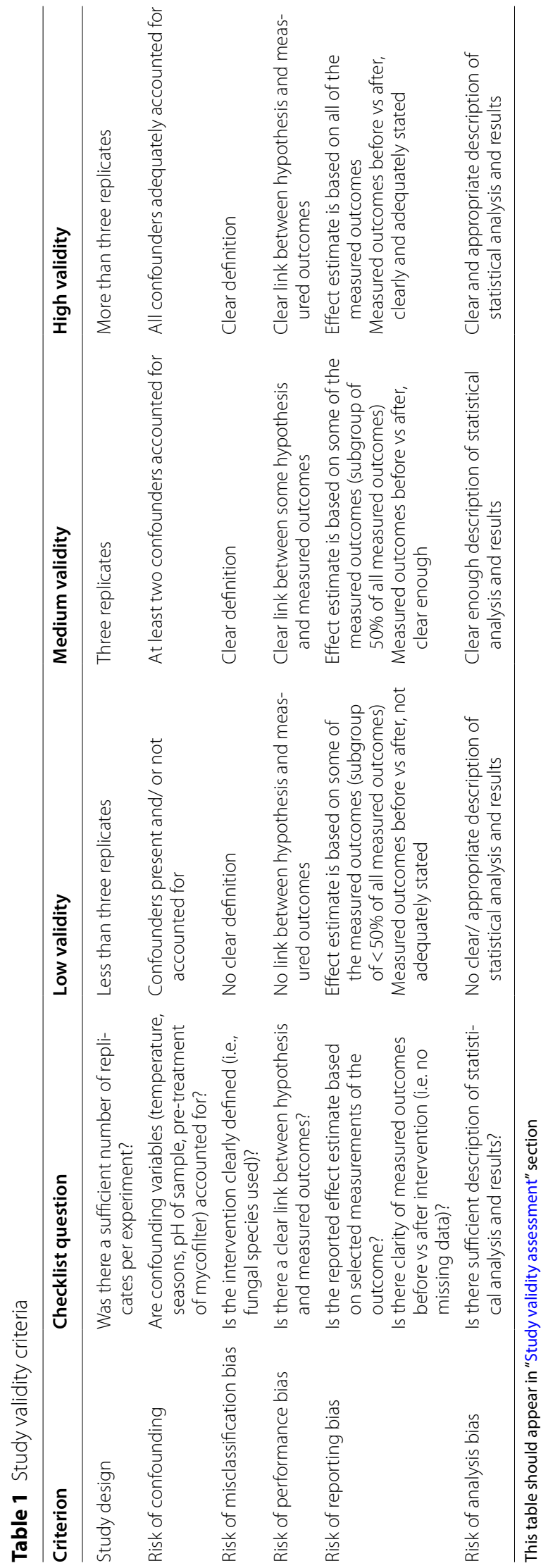


Table 2 Data coding

\begin{tabular}{|c|c|c|}
\hline Code & Variable & Description \\
\hline \multirow[t]{4}{*}{ Bibliographic information } & Author & Only last name of the first author, and et. al., for the other colleagues \\
\hline & Publication year & Year the paper was published \\
\hline & Title & Full title of the paper \\
\hline & Source of publication & Nature of the publication e.g., journal article, report etc., \\
\hline Study location & Country & The country where the study was conducted \\
\hline Study site & Field/Laboratory & If the study is based in the field or laboratory \\
\hline Seasonality & Season & The season (s) in which the study was carried out e.g., summer, winter etc. \\
\hline Water source & Sample nature & $\begin{array}{l}\text { Nature of the water sample subjected to filtration, e.g., river water, storm- } \\
\text { water, effluent etc., }\end{array}$ \\
\hline Fungus species & Species name (s) & Fungal species employed in the filtration study e.g., P. ostreatus \\
\hline Substrate employed & Substrate & Nature of the substrate used to create mycofilter e.g., wheat straw \\
\hline \multirow[t]{4}{*}{ Types of contaminants removed } & Organic contaminants & Specific organic contaminants reported, e.g., pesticides \\
\hline & Inorganic contaminants & Specific inorganic contaminants reported, e.g., heavy metals \\
\hline & Microbial contaminants & Specific bacterial contaminants reported, e.g., E. coli \\
\hline & Contaminant limit of detection & Lowest concentration of the contaminant that can be reliably detected \\
\hline Mycofiltration procedure duration & Time length & $\begin{array}{l}\text { The total length of time the mycofiltration procedure ran (minutes, hours, } \\
\text { days etc.) }\end{array}$ \\
\hline \multirow[t]{2}{*}{ Mycofilter unit design and set-up } & Design & Experimental design, stating if it is a single- or double-unit filter etc., \\
\hline & Set-up & $\begin{array}{l}\text { Stating the nature of the set-up, whether it is a continuous flow or a batch } \\
\text { system }\end{array}$ \\
\hline \multirow[t]{2}{*}{$\begin{array}{l}\text { Reported levels of contaminants } \\
\text { pre- and post- mycofiltration }\end{array}$} & Contaminant levels pre-mycofiltration & $\begin{array}{l}\text { Concentrations/ levels expressed in parts per million (ppm) and/ or parts } \\
\text { per billion (ppb) }\end{array}$ \\
\hline & Contaminant levels post-mycofiltration & $\begin{array}{l}\text { Concentrations/ levels expressed in parts per million (ppm) and/ or parts } \\
\text { per billion (ppb) }\end{array}$ \\
\hline Comparator & Control & Nature of the study/ experiment control, i.e., no fungal filter \\
\hline
\end{tabular}

This table should appear in "Data coding and extraction strategy" section

\section{Data coding and extraction strategy}

Using Ms Excel, evidence tables of meta-data and data extraction (i.e., study findings) will be produced in an MS-Excel spreadsheet. For each screened study that fits the inclusion criteria and meet the study validity criteria, data will be extracted according to pre-determined codes shown in Table 2. The following data will be coded for:

"Bibliographic information (author, year, title, source of publication e.g., article).

"Study location (country).

"Study site (field/ laboratory).

"Seasonality (i.e. season in which the study was conducted).

"Water source (e.g. stormwater, effluent, dam water etc.).

"Fungus species (e.g. S. rugoso-annulata, P. ostreatus etc.).

"Substrate employed (e.g. wood chips, wheat straw etc.).

"Types of contaminants removed (e.g. heavy metals, $E$. coli, pesticides etc.) and contaminant limits of detection.

"Mycofiltration procedure duration.
"Mycofilter unit design and set-up (e.g., single/double filter; continuous flow/batch filtration).

*Reported levels of contaminants before mycofiltration, expressed in parts per million (ppm) and/ or parts per billion ( $\mathrm{ppb}$ ). If concentrations are not stated, data represented graphically will be extracted using the Web Plot Digitizer online tool [24]

* Reported levels of contaminants after mycofiltration, expressed in parts per million (ppm) and/ or parts per billion (ppb). If concentrations are not stated, data represented graphically will be extracted using the Web Plot Digitizer online tool [24]

"Comparator (description of the control with no biological filter, i.e., no intervention).

Data extraction will be carried out simultaneously by two reviewers to ensure extraction is conducted in a manner that is consistent and repeatable. Any differences between reviewers will be resolved through dialogue. In the event that relevant data is either missing or ambiguous, the corresponding authors of those studies will be contacted. 


\section{Potential effect modifiers and reasons for heterogeneity}

The identified potential effect modifiers and sources for heterogeneity are listed below. Also mentioned are the methods of testing.

"Study site (laboratory/ field) [subgroup analysis].

"Mycofiltration procedure duration (meta regression/ subgroup analysis).

"Mycofilter unit set-up (e.g., single/double filter; continuous flow/batch filtration) [subgroup analysis].

"Water source [subgroup analysis].

A final list of effect modifiers will be established and recorded in the narrative synthesis.

\section{Data synthesis and presentation}

After data extraction from all eligible studies, those demonstrating low risk of bias (based on study validity assessment), a narrative descriptive synthesis will be conducted, summarising information in tables and figures. Summaries will be descriptive, outlining bibliographic information, study location and site, population, fungi species employed in the intervention, mycofilter procedure duration, types of contaminants removed as well as removal efficiency. If unreported in a study, removal efficiency for each contaminant will be calculated as follows:

$$
\% \text { removal efficiency }=\frac{(B F c-A F c)}{B F c} * 100
$$

where $\mathrm{BF}_{\mathrm{c}}=$ concentration before filtration and $\mathrm{AF}_{\mathrm{c}}=$ concentration after filtration.

Risk of publication bias will be performed through funnel plots. Where the evidence base allows, efforts will be made to provide a quantitative assessment of the intervention (i.e., contaminant removal after mycofiltration relative to the comparator) to determine effect size. A random effects model will be applied for meta-analysis. Meta-regressions or subgroup analysis of categories of studies will be performed where studies report common sources of heterogeneity. Sensitivity analysis will be performed by including or excluding studies of high risk of bias, to test robustness of reported findings.

The overall aim of this review is to identify, evaluate and summarise all types of contaminants removed by the mycofiltration technology, as well as assess the contaminant removal efficiency. The review will make the available evidence more accessible to researchers and environment management agencies invested in this technology.

\section{Supplementary Information}

The online version contains supplementary material available at https://doi. org/10.1186/s13750-021-00232-0.

Additional file 1. ROSES checklist.

Additional file 2. Benchmark articles.

Additional file 3. Search strings.

Acknowledgements

Not applicable.

\section{Authors' contributions}

The review question was developed by both SMM and PVO. Development of the systematic review protocol was led by SMM, with input from PVO. PVO provided overall scientific expertise. Both authors contributed to the manuscript write up and proofread. Both authors read and approved the final manuscript.

Funding

This research forms part of a Water Resources Management Project funded by the Afromontane Research Unit, University of the Free State, South Africa [Entity number 2-119-C3353]. SMM is supported by the Organization for Women in Science for the Developing World (OWSD) PhD Fellowship.

Availability of data and materials

Not applicable.

\section{Declarations}

Ethics approval and consent to participate Not applicable.

Consent to publish

Not applicable.

\section{Competing interests}

Authors declare they have no competing interests.

\section{Author details}

${ }^{1}$ Ecotoxicology Research Group, Afromontane Research Unit, Faculty of Natural and Agricultural Sciences, University of the Free State, Qwaqwa, South Africa. ${ }^{2}$ Ecotoxicology Research Group, Department of Applied Biology and Biochemistry, National University of Science and Technology, Bulawayo, Zimbabwe.

Received: 5 December 2020 Accepted: 19 July 2021

Published online: 28 July 2021

\section{References}

1. Akpaj E, Olorunfemi D. Mycofiltration effectiveness in bioremediation of contaminated drinking water sources. Ife J Sci. 2014;16:3.

2. Edokpayi J, Odiyo J, and Durowoju O. Impact of wastewater on surface water quality in developing countries: A case study of South Africa, in Water Quality, H. Tutu, Editor. 2017. InTech. 401-416.

3. Khatri N, Tyagi S. Influences of natural and anthropogenic factors on surface and groundwater quality in rural and urban areas. Front Life Sci. 2015;8(1):23-39.

4. Akpor OB, Ohiobor GO, Olaolu TD. Heavy metal pollutants in wastewater effluents: Sources, effects and remediation. Adv Biosci Bioeng. 2014;2(4):37-43.

5. Akpor OB, Muchie M. Environmental and public health implications of wastewater quality. Afr J Biotechnol. 2011;10(13):2379-87. 
6. Wu Y, Chen J. Investigating the effects of point source and nonpoint source pollution on the water quality of the East River (Dongjiang) in South China. Ecol Indic. 2013; 32 294-304.

7. Sankaran S, Khanal SK, Jasti N, Jin B, Pometto AL, Van Leeuwen JH. Use of filamentous fungi for wastewater treatment and production of high value fungal byproducts: a review. Crit Rev Environ Sci Technol. 2010:40(5):400-49.

8. Hamba Y, Tamiru M. Mycoremediation of heavy metals and hydrocarbons contaminated environment. Asian J Nat Appl Sci. 2016;5:2.

9. Kulshreshtha S, Mathur N, Bhatnagar P. Mushroom as a product and their role in mycoremediation. AMB Express. 2014;4:29-29.

10. Singh H. Mycoremediation: Fungal Bioremediation. New Jersey: John Wiley \& Sons Inc.; 2006.

11. Bishnoi RN, Garima. . Fungus- an alternative for bioremediation of heavy metal containing wastewater: a review. J Sci Ind Res. 2005;2005(64):93-100.

12. Boamponsem G, Obeng A, Osei-Kwateng M, Badu A. Accumulation of heavy metals by Pleurotus ostreatus from soils of metal scrap sites. Int J Curr Res Rev. 2013;5:4

13. Camacho $L$ and Sánchez J. Biotechnological use of fungi for the degradation of recalcitrant agro-pesticides. 2015; 12.

14. Golan-Rozen N, Chefetz B, Ben-Ari J, Geva J, Hadar Y. Transformation of the recalcitrant pharmaceutical compound carbamazepine by Pleurotus ostreatus: Role of cytochrome P450 monooxygenase and manganese peroxidase. Environ Sci Technol. 2011;45(16):6800-5.

15. Taylor A, Flatt A, Beutel M, Wolff M, Brownson K, Stamets P. Removal of Escherichia coli from synthetic stormwater using mycofiltration. Ecol Eng. 2015;78:79-86.

16. Stamets, P., Mycelium Running: How mushrooms can help save the world. 2005: Potter/TenSpeed/Harmony.
17. Sanyaolu A, Olugbenga S. The biofiltration potentials of a brewery effluent using two saprophytic fungi species. Annu Res Rev Biol. 2014:4(24):4004-22.

18. Olorunfemi D, Efechuku U, Esuana J. Toxicological evaluation of drinking water sources in some rural communities in southern nigeria after mycofiltration treatment. Pol J Environ Stud. 2015;24:1.

19. Thomas SA, Aston LM, Woodruff DL. Field demonstrations of mycoremediation for removal of fecal coliform bacteria and nutrients in the dungeness watershed, washington. 2009. Pacific Northwest National Laboratory. Washington.

20. Moloi M, Ogbeide O, and Voua Otomo P. Probabilistic health risk assessment of heavy metals at wastewater discharge points within the Vaal river basin, South Africa. Int J Hyg Environ Health. 2020; 224113421

21. http://www.reservoir.co.za. Accessed 20 Jan 2021.

22. Pullin AS, Frampton GK, Livoreil B, Petrokofsky G, and Edelstein KE. Collaboration for Environmental Evidence. 2018. Guidelines and standards for evidence synthesis in environmental management. Version 5.0. www. environmentalevidence.org/information-for-authors. 2018. Accessed 26 Oct 2020.

23. Konno K, Livoreil B, and Pullin AS. 2021. Collaboration for Environmental Evidence Critical Appraisal Tool version 0.2 (prototype)

24. http://arohatgi.info/WebPlotDigitizer/app/?. Accessed 06 Apr 2021.

\section{Publisher's Note}

Springer Nature remains neutral with regard to jurisdictional claims in published maps and institutional affiliations.
Ready to submit your research? Choose BMC and benefit from:

- fast, convenient online submission

- thorough peer review by experienced researchers in your field

- rapid publication on acceptance

- support for research data, including large and complex data types

- gold Open Access which fosters wider collaboration and increased citations

- maximum visibility for your research: over $100 \mathrm{M}$ website views per year

At $\mathrm{BMC}$, research is always in progress.

Learn more biomedcentral.com/submissions 